\title{
Fasudil improves survival and promotes skeletal muscle development in a mouse model of spinal muscular atrophy
}

Melissa Bowerman ${ }^{1,2}$, Lyndsay M Murray ${ }^{1}$, Justin G Boyer ${ }^{1,2}$, Carrie L Anderson ${ }^{1}$ and Rashmi Kothary ${ }^{1,2,3^{*}}$

\begin{abstract}
Background: Spinal muscular atrophy (SMA) is the leading genetic cause of infant death. It is caused by mutations/deletions of the survival motor neuron 1 (SMN1) gene and is typified by the loss of spinal cord motor neurons, muscular atrophy, and in severe cases, death. The SMN protein is ubiquitously expressed and various cellular- and tissue-specific functions have been investigated to explain the specific motor neuron loss in SMA. We have previously shown that the RhoA/Rho kinase (ROCK) pathway is misregulated in cellular and animal SMA models, and that inhibition of ROCK with the chemical Y-27632 significantly increased the lifespan of a mouse model of SMA. In the present study, we evaluated the therapeutic potential of the clinically approved ROCK inhibitor fasudil.
\end{abstract}

Methods: Fasudil was administered by oral gavage from post-natal day 3 to 21 at a concentration of $30 \mathrm{mg} / \mathrm{kg}$ twice daily. The effects of fasudil on lifespan and SMA pathological hallmarks of the SMA mice were assessed and compared to vehicle-treated mice. For the Kaplan-Meier survival analysis, the log-rank test was used and survival curves were considered significantly different at $P<0.05$. For the remaining analyses, the Student's two-tail $t$ test for paired variables and one-way analysis of variance (ANOVA) were used to test for differences between samples and data were considered significantly different at $P<0.05$.

Results: Fasudil significantly improves survival of SMA mice. This dramatic phenotypic improvement is not mediated by an up-regulation of Smn protein or via preservation of motor neurons. However, fasudil administration results in a significant increase in muscle fiber and postsynaptic endplate size, and restores normal expression of markers of skeletal muscle development, suggesting that the beneficial effects of fasudil could be muscle-specific.

Conclusions: Our work underscores the importance of muscle as a therapeutic target in SMA and highlights the beneficial potential of ROCK inhibitors as a therapeutic strategy for SMA and for other degenerative diseases characterized by muscular atrophy and postsynaptic immaturity.

Keywords: spinal muscular atrophy, fasudil, survival motor neuron protein, NMJ, muscle

\section{Background}

As the leading genetic cause of infant deaths, spinal muscular atrophy (SMA) is a devastating and incurable neuromuscular disorder [1,2]. SMA affects 1 in 6,000 to 10,000 births and results from deletions or mutations in the survival motor neuron 1 (SMN1) gene [1-3]. The

\footnotetext{
* Correspondence: rkothary@ohri.ca

'Ottawa Hospital Research Institute, 501 Smyth Road, Ottawa, ON, Canada $\mathrm{K} 1 \mathrm{H} 8 \mathrm{~L} 6$

Full list of author information is available at the end of the article
}

primary pathological hallmark of SMA is the loss of lower motor neurons from the spinal cord and corresponding muscular atrophy with subsequent paralysis and in most severe cases, death $[1,2]$.

The complete loss of the SMN protein is embryonic lethal [4]. In humans however, a recent duplication event in chromosome 5 has given rise to the centromeric SMN2 gene [3]. While both SMN1 and SMN2 genes differ by only a few nucleotides, a critical $\mathrm{C}$ to $\mathrm{T}$ substitution lies within position 6 of SMN2 exon 7 [5,6].

\section{Ciomed Central}


This silent mutation results in the aberrant splicing of exon 7 , giving rise to the biologically unstable SMN $\Delta 7$ protein $[3,5]$. Although the SMN2 gene produces predominantly the SMN $\Delta 7$ protein, a small amount of fulllength SMN is still produced [3]. Thus, the number of SMN2 gene copies in SMA patients is a key modifier of disease severity $[3,7,8]$.

One of the major hurdles in SMA is to understand how the loss of a ubiquitously expressed protein leads to the specific loss of spinal cord motor neurons. Work from various research groups has identified distinct roles for SMN in neurodevelopment, neuromaintenance, RNA metabolism, at the neuromuscular junction (NMJ) and in skeletal muscle (reviewed in [9]). As of yet however, none of these various functions of the SMN protein have been recognized as being solely responsible for SMA pathogenesis.

Work from our laboratory has shown that Smn depletion in cellular and mouse models results in altered expression and localization of a number of regulators of actin cytoskeletal dynamics [10-12]. Indeed, analysis of spinal cords from SMA mice revealed a significant increase in active RhoA (RhoA-GTP) [12], a major upstream regulator of the actin cytoskeleton [13]. RhoAGTP signaling in neuronal cells modulates various cellular functions such as growth, neurite formation, polarization, regeneration, branching, pathfinding, guidance and retraction (reviewed in $[14,15]$ ). Our previous work demonstrated that administration of the RhoA/Rho kinase (ROCK) inhibitor Y-27632 [16] leads to a dramatic increase in survival in an intermediate mouse model of SMA [12]. Recently Nölle et al. demonstrated that knockdown of Smn in PC12 cells affects the phosphorylation state of downstream effectors of ROCK, supporting the value of the ROCK pathway as a therapeutic target for SMA pathogenesis [17].

In the present work, we have treated SMA mice with fasudil, a ROCK inhibitor approved for US clinical trials. We show that fasudil dramatically improves the lifespan and increases muscle fiber size in $S m n^{2 B /-}$ SMA mice. Furthermore, we report for the first time that ROCK inhibition restores normal expression of markers of skeletal muscle development in SMA mice. Our study highlights the beneficial effects of ROCK inhibition not only for SMA pathogenesis but also for any degenerative disease that has NMJ and skeletal muscle development defects. Importantly, as fasudil is currently being used in US Food and Drug Administration (FDA)-approved clinical trials for other disorders, re-purposing it is an exciting and feasible therapeutic approach for the treatment of SMA.

\section{Methods}

\section{Animal models}

The $S m n^{2 B /-}$ mice were established in our laboratory and maintained in our animal facility on a C57BL/6 $\times$
CD1 hybrid background. The 2B mutation consists of a substitution of three nucleotides in the exon splicing enhancer of exon $7[18,19]$. The Smn knock-out allele was previously described by Schrank et al. [20] and Smn +/- mice were obtained from The Jackson Laboratory (Bar Harbor, Maine, USA). All animal procedures were performed in accordance with institutional guidelines (Animal Care and Veterinary Services, University of Ottawa).

\section{Fasudil administration}

Fasudil (LC Laboratories; Woburn, Massachusetts, USA) was diluted in water and administered by a modified oral gavage procedure [21] to $S m n^{2 B /-}$ and $S m n^{2 B /+}$ mice from post-natal day (P)3 to P21. The three fasudil dosage regimens were as follows: low dose $(30 \mathrm{mg} / \mathrm{kg}$ once daily), medium dose (30 mg/kg twice daily), and high dose $(30 \mathrm{mg} / \mathrm{kg}$ twice daily from P3 to P6; $50 \mathrm{mg} /$ $\mathrm{kg}$ twice daily from P7 to P13; $75 \mathrm{mg} / \mathrm{kg}$ twice daily from P14 to P21). Vehicle-treated animals received water. Survival and weight were monitored daily.

\section{Antibodies}

The primary antibodies used were as follows: mouse anti-actin (1:800; Fitzgerald; Acton, Massachusetts, USA), mouse anti-Smn (1:5000; BD Transduction Laboratories; Mississauga, Ontario, Canada), rabbit antiphosphorylated cofilin (1:250; Chemicon; Billerica, Massachusetts, USA), rabbit anti-cofilin (1:500; Millipore; Billerica, Massachusetts, USA), rabbit anti-phosphorylated cofilin 2 (1:500; Cell Signaling; Danvers, Massachusetts, USA), rabbit anti-cofilin 2 (1:500; Millipore), mouse anti-myogenin (1:250; BD Transduction Laboratories), rabbit anti-HB9 (1:50; Abcam; Cambridge, Massachusetts, USA), mouse anti-2H3 (1:250; Developmental Studies Hybridoma Bank; Iowa City, Iowa, USA) and mouse anti-SV2 (1:250; Developmental Studies Hybridoma Bank). The secondary antibodies used were as follows: horseradish peroxidase (HRP)-conjugated goat anti-mouse IgG (1:5000; Bio-Rad; Mississauga, Ontario, Canada), HRP-conjugated goat antirabbit IgG (1:5000; Bio-Rad), DyLight goat anti-mouse (1:250; Jackson ImmunoResearch; West Grove, Pennsylvania, USA), goat anti-rabbit biotin-SP-conjugated (1:200; Dako; Burlington, Ontario, Canada)), streptavidin-Cy3-conjugated (1:600; Jackson ImmunoResearch) and Alexa Fluor 680 goat anti-mouse (1:5000; Molecular Probes; Burlington, Ontario, Canada). The $\alpha$-bungarotoxin (BTX) conjugated to tetramethylrhodamine isothiocyanate was from Molecular Probes $(5 \mu \mathrm{g} / \mathrm{mL})$.

\section{Immunoblot analysis}

Equal amounts of spinal cord and tibialis anterior (TA) muscle tissue extracts were separated by electrophoresis 
on 10\% SDS-polyacrylamide gels and blotted onto nitrocellulose membranes (Amersham; Baie d'Urfe, Quebec, Canada). The membranes were blocked in $5 \%$ non-fat milk in TBST (10 mM Tris- $\mathrm{HCl} \mathrm{pH} \mathrm{8.0,} 150 \mathrm{mM} \mathrm{NaCl}$, and $0.1 \%$ Tween 20 (Sigma; Oakville, Ontario, Canada)). Membranes were incubated overnight at $4{ }^{\circ} \mathrm{C}$ with primary antibody, followed by a one-hour incubation with the secondary antibody. All washes were performed with TBST. Signals were visualized using the ECL or the ECL plus detection kit (Amersham). Exposure times were chosen based on the saturation of the highest amounts of protein.

\section{Hematoxylin and eosin staining}

Spinal cord (L1-L2 lumbar regions) and TA muscle sections $(5 \mu \mathrm{m})$ were deparaffinized in xylene and fixed in $100 \%$ ethanol. Following a rinse in water, samples were stained in hematoxylin (Fisher; El Paso, Texas, USA) for three minutes, rinsed in water, dipped 40 times in a solution of $0.02 \% \mathrm{HCl}$ in $70 \%$ ethanol and rinsed in water again. The sections were stained in a $1 \%$ eosin solution (BDH; Billerica, Massachusetts, USA) for one minute, dehydrated in ethanol, cleared in xylene and mounted with Permount (Fisher). Images were taken with a Zeiss Axioplan2 microscope, with a $20 \times$ objective.

Quantitative assays were performed on three mice for each genotype and five sections per mouse. Motor neurons were identified by their shape and size ( $>10 \mu \mathrm{m}$ in diameter) in the same designated area of the ventral horn region of the spinal cord. Every fifth section was analyzed and the subsequent totals were multiplied by five to give an estimate of total motor neuron number. Only motor neurons with visible nuclei were counted so as to prevent double-counting. For TA quantitative assays, the area of muscle fiber within designated regions of the TA muscle sections was measured using the Zeiss AxioVision software.

\section{Immunohistochemistry}

For immunohistochemistry, spinal cord sections were first deparaffinized in xylene $(3 \times 10$ minutes), fixed in $100 \%$ ethanol ( $2 \times 10$ minutes), rehydrated in $95 \%$ and $75 \%$ ethanol (5 seconds each) and placed for 5 minutes in $1 \mathrm{M}$ Tris- $\mathrm{HCl} \mathrm{pH}$ 7.5. Sections were then placed in boiling sodium citrate antigen retrieval buffer $(10 \mathrm{mM}$ sodium citrate, $0.05 \%$ Tween $20, \mathrm{pH} 6.0$ ) for 20 minutes in the microwave. The sections were rinsed for $10 \mathrm{~min}$ utes under running cold tap water and incubated for 2 hours at room temperature (RT) in blocking solution (TBLS $\left(10 \% \mathrm{NaN}_{3}\right), 20 \%$ goat serum, $0.3 \%$ Triton X-100). This was followed by an overnight incubation at $4^{\circ} \mathrm{C}$ with the primary antibody. Subsequently, sections were incubated for 1 hour at RT with the biotinylated rabbit antibody followed by a 1 hour incubation at RT with
streptavidin-Cy3. All washes were done with PBS. Hoechst $(1: 1000)$ was added to the last PBS wash followed by the slides being mounted in fluorescent mounting medium (Dako). Images were taken with a Zeiss confocal microscope, with a $20 \times$ objective, equipped with filters suitable for $\mathrm{Cy} 3 / \mathrm{Hoechst}$ fluorescence.

\section{Neuromuscular junction immunohistochemistry}

Transversus abdominis (TVA) and TA muscle sections were labeled by immunohistochemistry to allow quantification of neuromuscular innervation as described previously $[12,22]$. Briefly, TVA muscles were immediately dissected from recently sacrificed mice and fixed in $4 \%$ paraformaldehyde (Electron Microscopy Science; Hatfield, Pennsylvania, USA) in PBS for 15 minutes. Postsynaptic acetylcholine receptors were labeled with $\alpha$ BTX for 10 minutes. Muscles were then permeabilized in $2 \%$ TritonX for 30 minutes and blocked in $4 \%$ bovine serum albumin/1\% TritonX in PBS for 30 minutes before incubation overnight in primary antibodies and visualized with DyLight-conjugated secondary antibodies. Whole TA muscles were dissected and fixed in $4 \%$ paraformaldehyde. Following the removal of connective tissue, the TA muscles were incubated with $\alpha$ BTX Alexa Fluor 555 conjugate for 20 minutes at RT. Whole TVA muscle and a thin filet of TA muscle were mounted in Dako fluorescent mounting media. Images were taken with a Zeiss confocal microscope equipped with filters suitable for fluorescein isothiocyanate (FITC)/Cy3/fluorescence. Categorization of pre- and postsynaptic morphologies was performed as previously reported [23].

\section{Pen test}

Balance and strength were assessed using the pen test as described [24]. Mice were placed on a suspended pen at different time-points (P12, 14, 17 and 21). The latency to fall from the pen was measured with a plateau of 30 seconds. At each time-point, individual mice were assessed three consecutive times.

\section{Statistical methods}

All statistical analyses were performed using the GraphPad Prism software. For the Kaplan-Meier survival analysis, the log-rank test was used and survival curves were considered significantly different at $P<0.05$. When appropriate, the Student's two-tail $t$ test for paired variables and one-way ANOVA were used to test for differences between samples and data were considered significantly different at $P<0.05$.

\section{Results}

Fasudil increases lifespan of $\mathrm{Smn}^{2 \mathrm{~B} /-}$ mice

The $S m n^{2 B}$ allele harbors a sequence change in the exon splicing enhancer of exon 7 of the murine Smn gene, 
leading to the predominant production of the $\operatorname{Smn} \Delta 7$ protein $[18,19]$. The $S m n^{2 B}$ allele in combination with the knockout allele results in an intermediate SMA mouse model $\left(S m n^{2 B /-}\right)$ with a median lifespan of 30 days that displays motor neuron loss, neuromuscular defects and immature NMJs [23]. We have previously shown that the ROCK inhibitor Y-27632 dramatically improved the lifespan of $S m n^{2 B /-}$ mice [12]. Since Y27632 has not been approved for clinical use, we set out to determine if the ROCK inhibitor, fasudil, which has been approved for US clinical trials [25], would have similar beneficial effects on the $S m n^{2 B /-}$ mice.

Treating the $S m n^{2 B /-}$ mice by gavage twice daily (30 $\mathrm{mg} / \mathrm{kg}$ dose) from P3 to P21 led to a significant increase in lifespan when compared to vehicle-treated $S m n^{2 B /-}$ mice (Figure 1A). Indeed, $57 \%$ of fasudil-treated $S m n^{2 B /-}$ mice survived over 300 days while the median survival of vehicle-treated $\mathrm{Smn}^{2 \mathrm{~B} / \text { - }}$ mice is 30.5 days (Figure 1A). A lower dose of fasudil had no effect while a higher dose was accompanied by a non-negligible toxicity (Additional file 1). Interestingly, both vehicle- and fasudil-treated $S m n^{2 B /-}$ mice showed a similar arrest in weight gain after P10 (Figure 1B). When assessing strength and balance via the pen test [24], both vehicleand fasudil-treated $S m n^{2 B /-}$ mice had short latencies to fall from the pen (Figure 1C). Thus, while fasudil significantly increased the lifespan of the $S m n^{2 B /-}$ mice, it did not influence the weight loss or the neuromuscular weakness that typifies this SMA mouse model [23]. However, when comparing mice past weaning age, we find that fasudil-treated $S m n^{2 B /-}$ mice are better groomed, move about more freely in the cage and display a less severe neurological phenotype than vehicletreated $S m n^{2 B /-}$ mice (Additional file 2). Additionally, despite their initial compromised body size and neuromuscular function, surviving fasudil-treated $S m n^{2 B /-}$ female mice are able to reproduce, as exemplified by a female that was euthanized because of dystocia (Figure 1A). The dystocia-linked death, however, highlights the breeding limitations in these aging fasudil-treated mice that still exhibit an SMA neuromuscular phenotype.

Fasudil activity in the spinal cord does not prevent motor neuron loss in $\mathrm{Smn}^{2 \mathrm{~B} /-}$ mice

The main goal of using fasudil as a therapeutic strategy is to compensate for the increased levels of RhoA-GTP in the spinal cords of the $S m n^{2 B /-}$ mice [12]. In order to investigate the mechanisms by which fasudil exerts its beneficial effects, we investigated its activity and impact on motor neuron loss in the spinal cord. Spinal cord extracts from P21 fasudil-treated $S m n^{2 B /-}$ mice showed a reduction in phosphorylated cofilin, a downstream effector of ROCK [26,27], when compared to vehicle-treated SMA mice (Figure 2A), demonstrating that oral administration of fasudil efficiently delivers the drug to the CNS and leads to an efficient inhibition of ROCK activity.

To investigate if the beneficial effects of fasudil administration are mediated through an increase in $\mathrm{Smn}$ expression, we compared Smn protein levels in P21 spinal cords of wild type, vehicle-treated and fasudiltreated $\mathrm{Smn}^{2 \mathrm{~B} /-}$ mice. This comparison shows that fasudil does not lead to a significant upregulation of Smn expression (Figure 2B) and further suggests that fasudil acts via an Smn-independent pathway to improve the survival of $S m n^{2 B /-}$ mice.

As a major hallmark of SMA is loss of lower motor neuron cell bodies from the spinal cord, we assessed the effect of fasudil on the motor neuron loss previously characterized in the $S m n^{2 B /-}$ mouse model $[11,23]$. Quantification of the number of motor neuron cell bodies in the ventral horn region of L1-L2 lumbar spinal cord sections revealed similar significant reductions in both vehicle- and fasudil-treated $S m n^{2 B /-}$ mice compared to wild type controls (Figure 2C, D). This implies that the beneficial effects observed following fasudil administration are not mediated via a preservation of motor neuron cell bodies. It is therefore possible that fasudil acts on other SMA-afflicted tissues and/or compartments that subsequently influence the functionality of the surviving motor neurons.

\section{Fasudil increases skeletal muscle fiber size}

In addition to motor neuron degeneration, SMA is also typified by muscular atrophy $[1,2]$. In recent years, several intrinsic pathologies and defective molecular pathways have been reported in SMA muscle ([28-30] and JGB, unpublished data). Furthermore, we have previously demonstrated that the ROCK inhibitor Y-27632 leads to an increase in the TA myofiber size of $\mathrm{Smn}^{2 \mathrm{~B} /}$ mice [12]. We thus investigated the effect of fasudil on skeletal muscle and show that TA muscles from fasudiltreated P21 Smn ${ }^{2 B /-}$ mice display significantly larger myofibers than vehicle-treated $S m n^{2 B /-}$ mice (Figure 3A, B). Indeed, both wild type and fasudil-treated $\mathrm{Smn}^{2 B /-}$ mice show similar myofiber sizes (Figure 3A, B). To determine whether this increase in muscle fiber size was SMA-dependent, we also compared TA muscles of vehicle- and fasudil-treated $S m n^{2 B /+}$ phenotypically normal littermates. This revealed no significant difference in myofiber size (Figure 3C, D), thus suggesting that fasudil acts on muscle-specific molecular pathways that are distinctly perturbed in the SMA mice.

\section{Fasudil-treated muscles display restored myogenin expression}

To assess if fasudil was active in skeletal muscle, we examined factors downstream of ROCK signaling. 


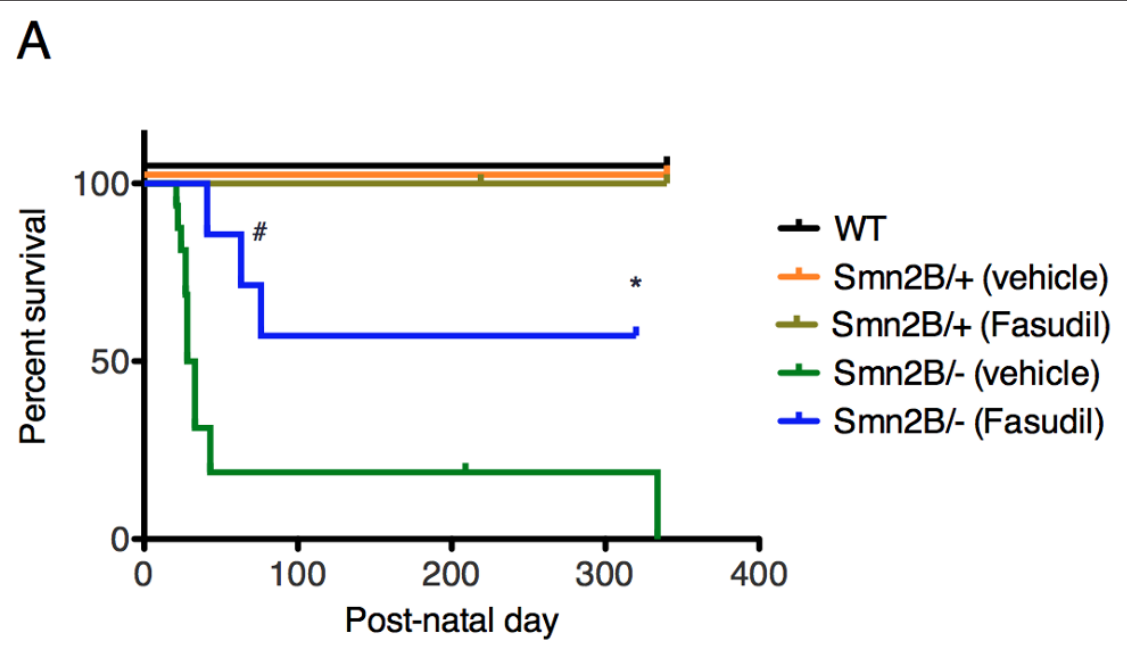

B

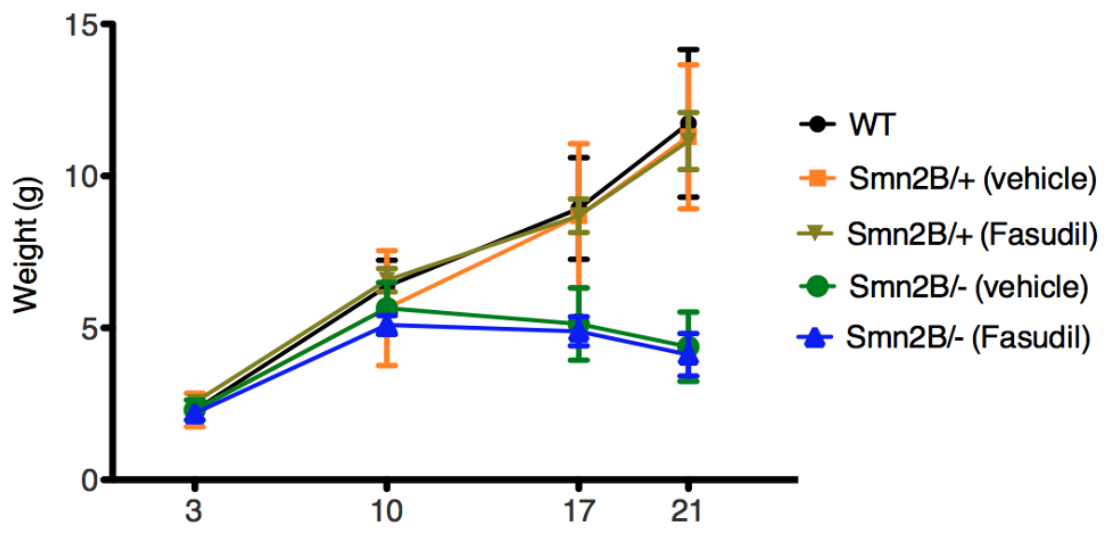

C

Post-natal day

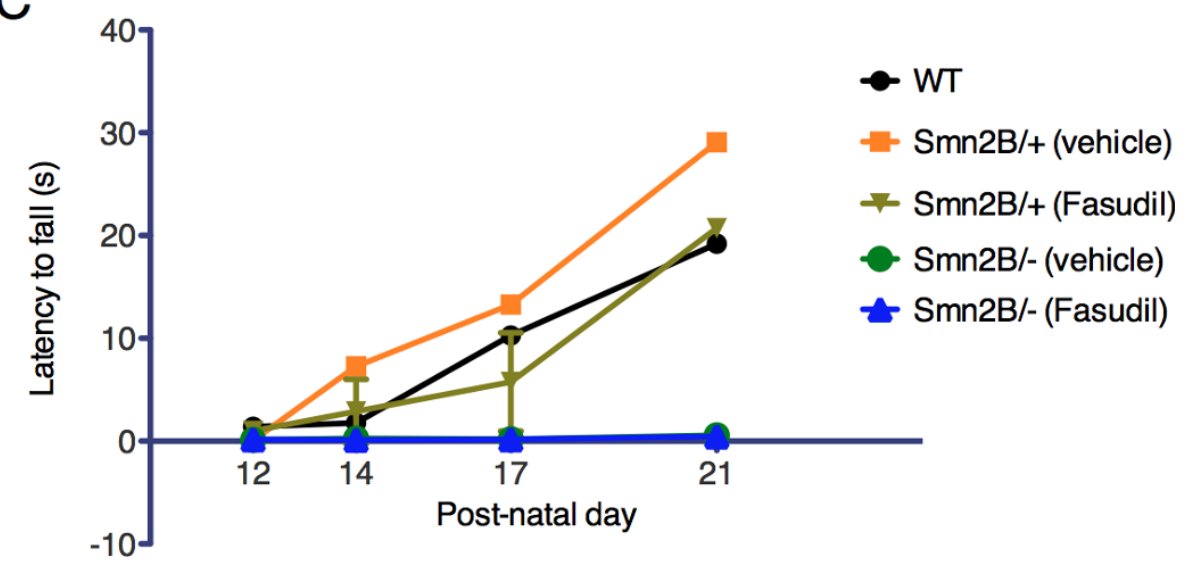

Figure 1 Fasudil increases lifespan of $S m n^{2 B /-}$ mice, independent of weight gain and pen test performance. Fasudil (30 mg/kg twice daily) or vehicle (water) was administered by gavage from post-natal (P) day 3 to P21. The different groups analyzed were: untreated wild type (WT) $(n=10)$, vehicle-treated $S m n^{2 B /+}(n=8)$, fasudil-treated $S m n^{2 B /+}(n=9)$, vehicle-treated $S m n^{2 B /-}(n=16)$ and fasudil-treated $S m n^{2 B /-}(n=7)$. (A) Fasudil significantly increases lifespan of $S m n^{2 B /-}$ mice when compared to vehicle-treated $S m n^{2 B /-}$ mice ${ }^{*} P=0.0251$; \# indicates death due to dystocia). Administration of fasudil does not have adverse effects on the lifespan of normal littermates. (B) Fasudil does not prevent the arrest in weight gain that occurs in vehicle-treated $S m n^{2 B /-}$ mice onwards of P10.(C) Fasudil does not improve the performance of Smn ${ }^{2 B /-}$ mice on the pen test when compared to vehicle-treated $S m n^{2 B /-}$ mice. 


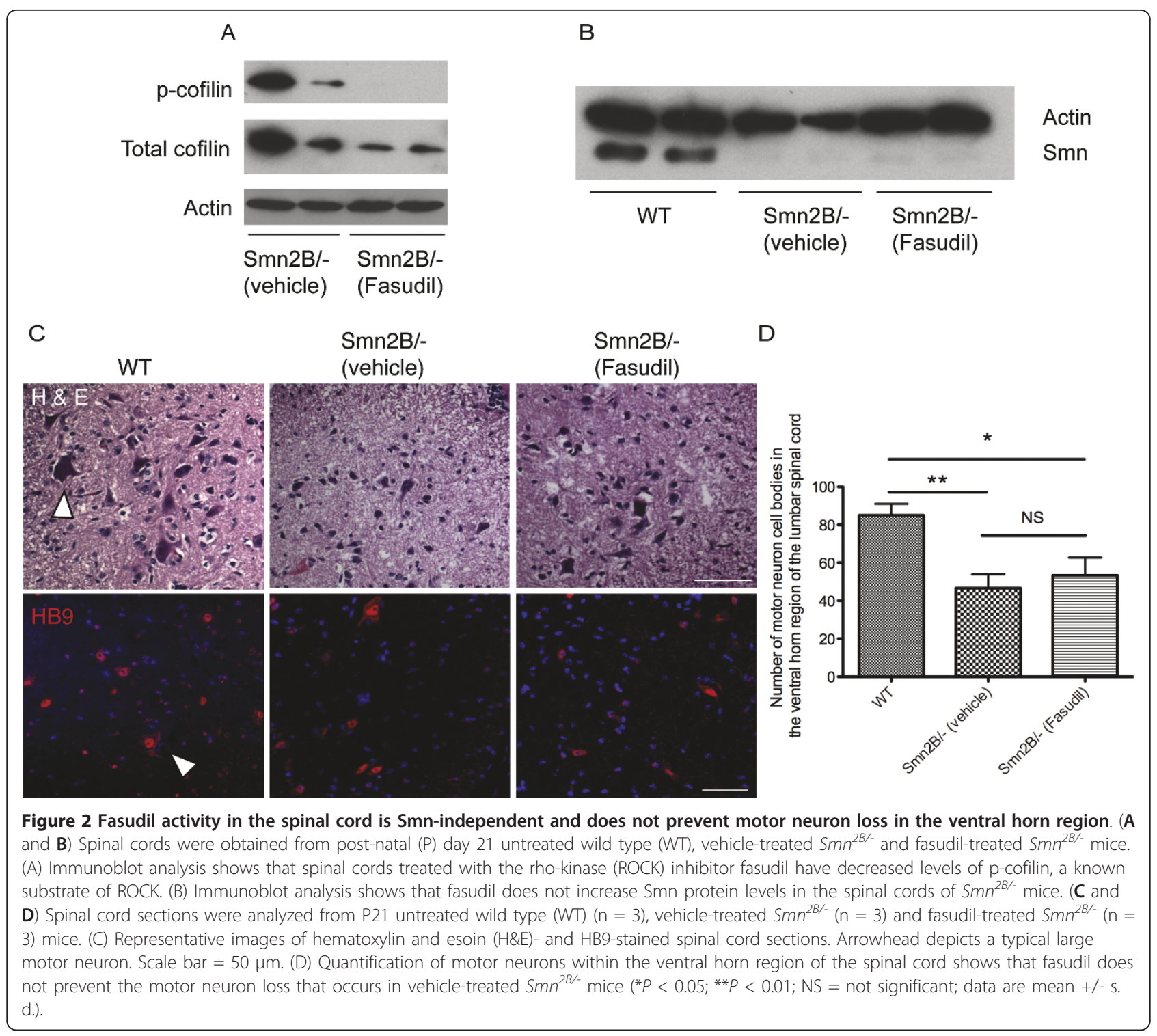

Cofilin 2 is a skeletal muscle-specific actin-regulating protein and downstream effector of activated ROCK $[31,32]$. We thus determined the impact of administrating fasudil by gavage on skeletal muscle by evaluating $\mathrm{p}$ cofilin 2 levels in vehicle- and fasudil-treated TA muscles from P21 mice. Interestingly, the TA muscles from $S m n^{2 B /-}$ mice have significantly higher levels of p-cofilin 2 protein than wild type muscles (Figure 4A, B), suggesting that the RhoA/ROCK pathway is also misregulated in skeletal muscle. Fasudil decreases p-cofilin 2 levels in $S m n^{2 B /-}$ muscle to wild type levels, indicating that it is active in the TA muscle and restores the normal ROCK/p-cofilin 2 levels (Figure 4A, B). We also show that fasudil does not upregulate $\mathrm{Smn}$ expression in the TA muscles of $S m n^{2 B /-}$ mice (Figure $4 C$ ). Thus, consistent with the spinal cord analysis (Figure $2 \mathrm{~B}$ ), it appears that the beneficial effects of fasudil in skeletal muscle are most likely Smn-independent.

Recent work from our laboratory suggests that hindlimb muscles from P21 Smn ${ }^{2 B /-}$ mice display defects in muscle development, as evidenced by the misregulation of myogenin (JGB, unpublished data), a transcription factor that plays a well-characterized role in myogenesis [33]. We thus investigated whether fasudil had any impact on myogenin levels. Analysis of TA muscles from P21 mice confirms the increased levels of myogenin in skeletal muscle of $S m n^{2 B /-}$ mice compared to wild type controls (Figure 4D, E). Importantly, fasudil administration leads to a significant decrease in myogenin levels in $S m n^{2 B /-}$ mice (Figure $4 \mathrm{D}, \mathrm{E}$ ). In fact, myogenin levels in fasudil-treated TA muscles are restored to wild type levels. Thus, fasudil returns the 


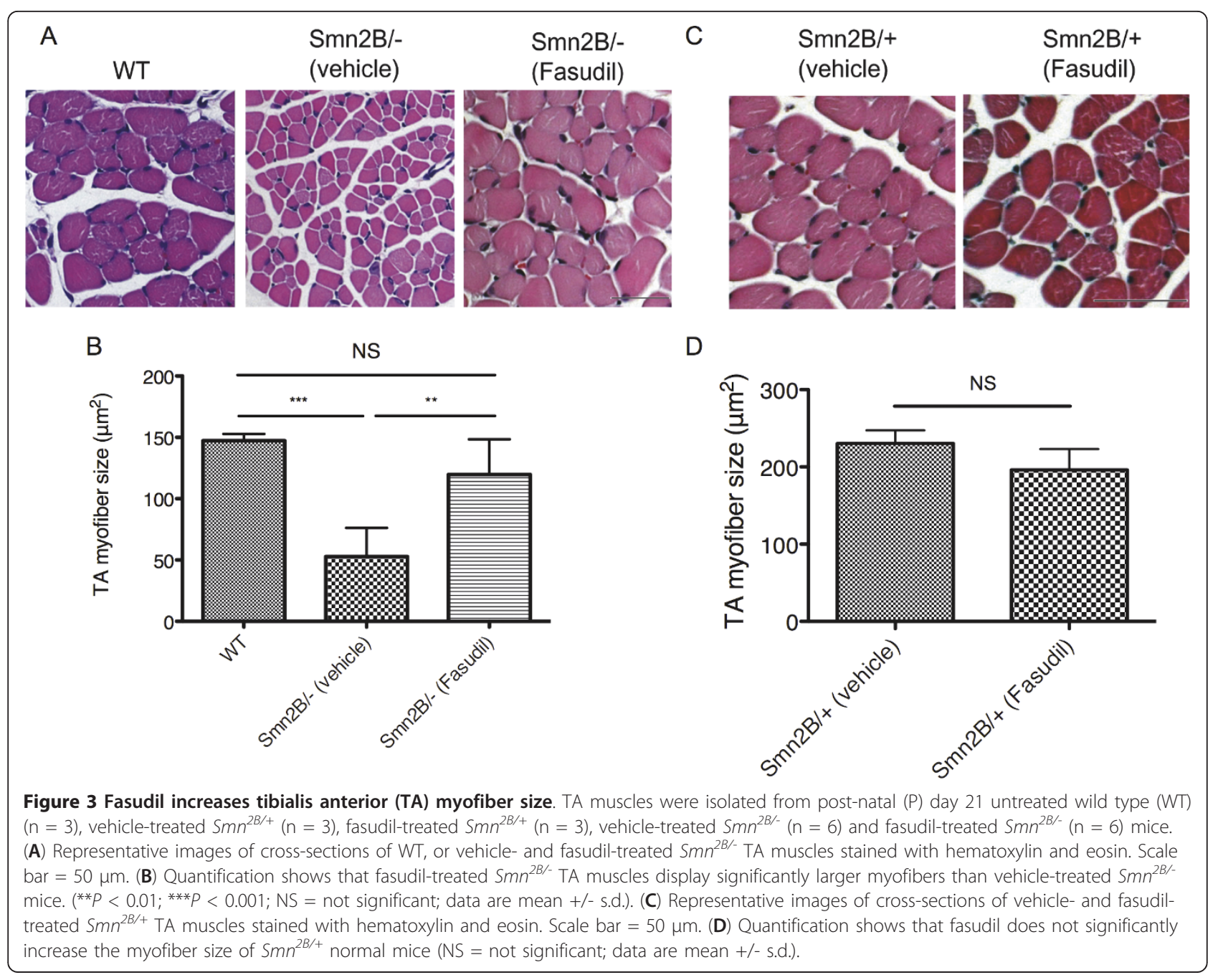

expression level of myogenin to normal, suggesting that fasudil may increase muscle size by restoring the typical development of skeletal muscle.

\section{Fasudil does not ameliorate the pre-synaptic phenotype} of NMJs from $\mathrm{Smn}^{2 \mathrm{~B} /-}$ mice

We have previously identified pre-synaptic pathology at the NMJ in the TVA of the $S m n^{2 B /-}$ mice, as evidenced by a loss of pre-synaptic inputs and accumulation of neurofilaments [23]. To determine if the reduction in muscle pathology observed following fasudil administration could be secondary to reduced pathology at the NMJ, an in-depth analysis was performed. This analysis was done on the TVA muscle of P21 late-symptomatic mice, which has previously been shown to display marked NMJ loss and pre-synaptic abnormalities [23]. The degree of pre-synaptic swelling, identified by neurofilament (NF) and synaptic vesicle 2 (SV2) staining, was classified into four categories based on morphology (type 1: normal, no pre-synaptic swelling observed; type 2: swollen, pre-synaptic terminal arborization is thickened compared to type 1 ; type 3: spheroid accumulations, spherical swellings accumulate over the NMJ; type 4: spheroid covers endplate (EP), spherical accumulations obscure the entire EP) (Figure $5 \mathrm{~A}$ ). While more than $80 \%$ of wild type terminals displayed a 'normal' pre-synaptic morphology, in both vehicle- and fasudil-treated $S m n^{2 B /-}$ mice we observed a high level of pre-synaptic swelling, with more than $50 \%$ of EPs displaying morphologies classified as types 2 to 4 (Figure $5 \mathrm{~B}$ ). Quantification of the number of fully innervated NMJs shows a significant decrease in both vehicle- and fasudil-treated $S m n^{2 B /-}$ mice when compared to wild type, with no significant difference observed between vehicle- and fasudil-treated SMA mice (Figure 5C). Thus, it appears, at least in P21 animals, that fasudil does not ameliorate the presynaptic phenotype observed in $S m n^{2 B /-}$ mice. This suggests that the improvement in muscle pathology we observe after fasudil administration is unlikely to be 


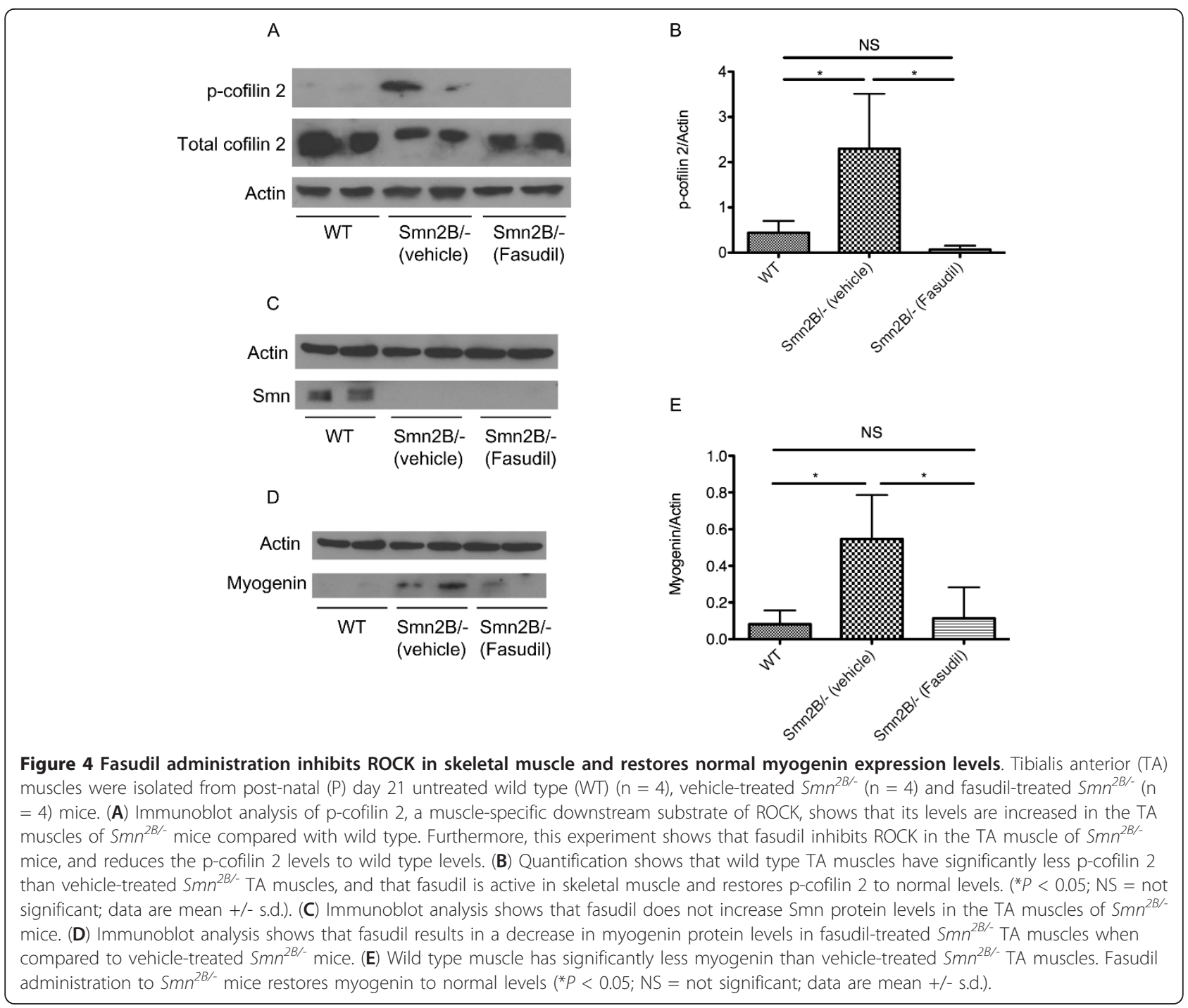

mediated through the NMJ, and that it likely is having a direct effect on the muscle.

\section{Fasudil increases endplate area of $\mathrm{Smn}^{2 \mathrm{~B} /-} \mathrm{NMJs}$}

We have previously shown that Y-27632 administration significantly increases the EP area of NMJs within the TA skeletal muscle [12]. We thus assessed the effect of fasudil on EP size in both the TA and the TVA of P21 mice. Fasudil-treated $S m n^{2 B /-}$ mice had significantly larger TA and TVA EP areas than vehicle-treated $S m n^{2 B /-}$ mice (Figure 6). Interestingly, this increase in EP area was weight-independent, since both vehicle- and fasudiltreated $\mathrm{Smn}^{2 \mathrm{~B} /-}$ mice display similar weight curves (Figure 1B). Our results suggest that while fasudil does not ameliorate the pathology evident at the pre-synaptic compartment of P21 Smn ${ }^{2 B /-}$ NMJs (Figure 5), there is a dramatic increase in the size of the post-synaptic compartment of NMJs within both muscles investigated
(Figure 6). Together, these results are consistent with the beneficial effects of fasudil being primarily mediated by the muscle and not the motor neuron.

\section{Increased NMJ maturation is observed in aging fasudil- treated $\mathrm{Smn}^{2 \mathrm{~B} /-}$ mice}

Although we saw no improvement in pre-synaptic NMJ pathology in P21 Smn ${ }^{2 B /-}$ mice, we wanted to evaluate the effect of fasudil over time on NMJ pathology. NMJs from the TVA muscle of P21 Fasudil-treated $S m n^{2 B /-}$ mice were compared to those of six month old fasudiltreated $S m n^{2 B /-}$ mice. Interestingly, we observed a marked decrease in pre-synaptic pathology in six month old mice compared to P21 mice, as evidenced by an increase in the percentage of fully occupied EPs (Figure 7A, B). This was accompanied by a dramatic increase in EP maturation (Figure 7C, D). We, therefore, suggest that although there was no initial improvement in the 


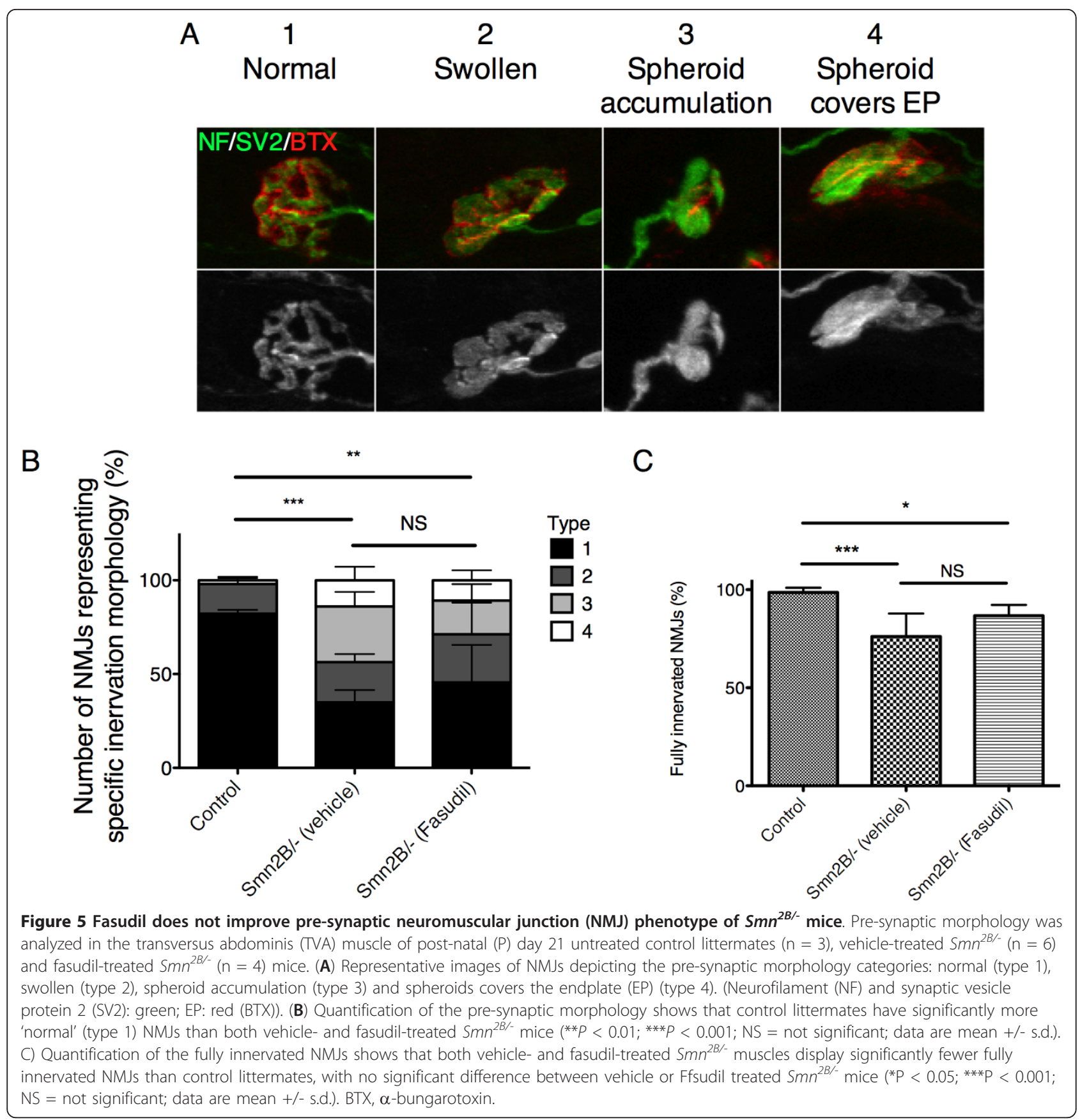

morphological aspects on NMJ pathology, given sufficient time, fasudil administration allows for the improved maturation of NMJs in $S m n^{2 B /-}$ mice.

\section{Discussion}

Previous work has implicated the RhoA/ROCK pathway in SMA pathogenesis $[10,12,17]$. In the present study, we demonstrate that targeting the ROCK pathway with the inhibitor fasudil significantly increases the lifespan of the $S m n^{2 B /-}$ SMA mice. The increased survival is independent of Smn expression, weight gain, pen test performance and pre-synaptic NMJ phenotype. We find, however, that fasudil benefits postsynaptic pathology and muscle development. Importantly, the results obtained from other fasudil clinical trials are proof-of-principle of its feasibility and availability as a therapeutic approach for the treatment of SMA. Future SMA clinical endeavors should therefore consider assessing the beneficial potential of ROCK inhibitors. 


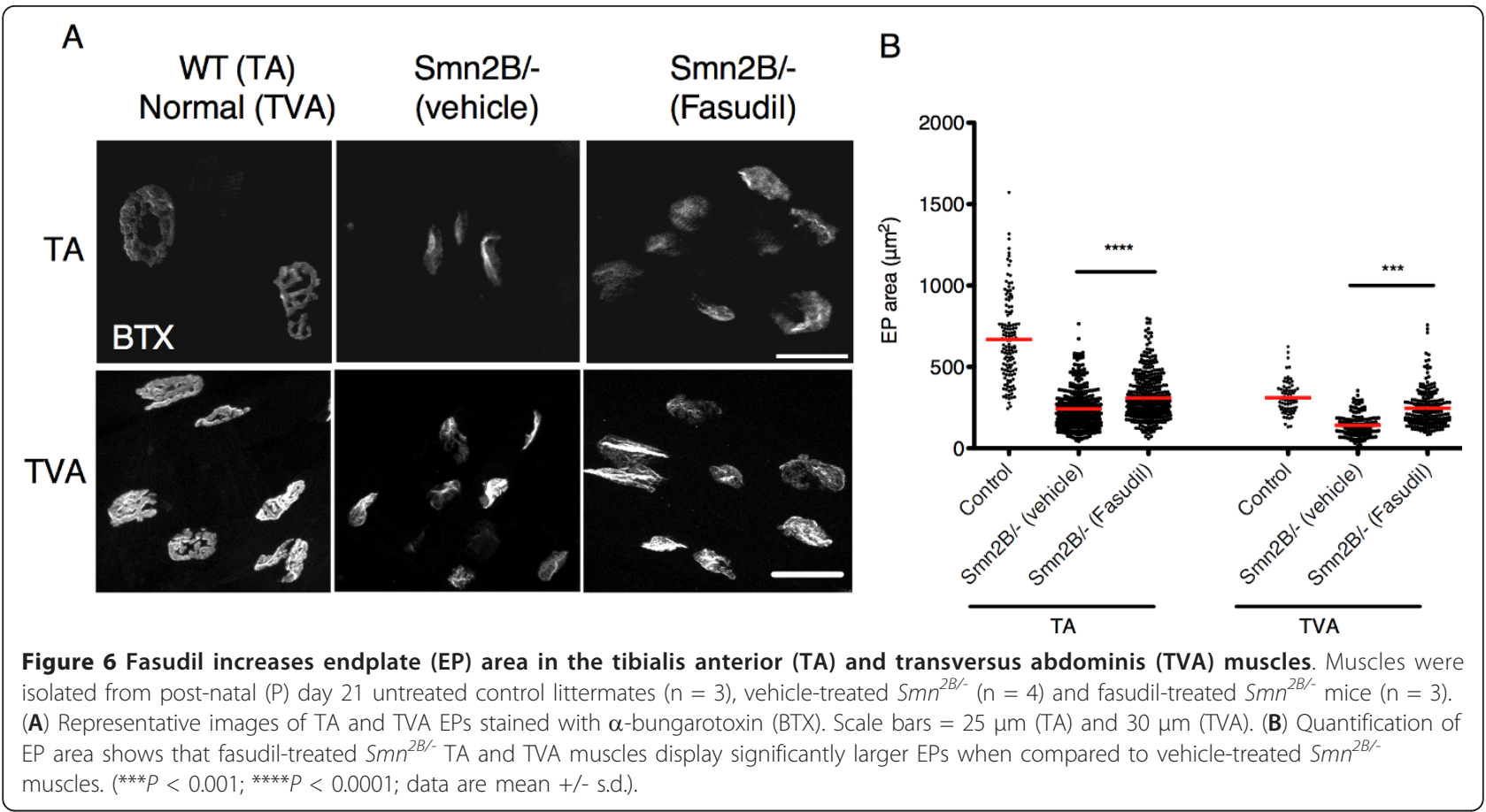

Smn protein levels remained significantly low in both fasudil-treated spinal cord and muscle samples of SMA mice. These findings are important when considering therapeutic avenues for SMA. There are presently many strategies being developed to increase the expression of SMN, such as gene therapy, modulation of transcription and splicing of SMN2, and the use of various histone deacetylase (HDAC) inhibitors (reviewed in [34-36]). Although these therapeutic approaches show promising results, they remain in pre-clinical stages and may not be as efficient if administered to mid- to late-symptomatic patients [37]. It is therefore crucial to understand the pathological molecular pathways that are affected upon SMN loss and how these can be modulated to attenuate their degenerative effects. Along with other research groups, we have shown that the RhoA/ROCK pathway is indeed perturbed in SMA cellular and animal models and that its targeting leads to a significant beneficial outcome [10,12,17].

We had previously identified the upregulation of RhoAGTP in the spinal cords of $S m n^{2 B /-}$ mice [12]. The misregulated RhoA/ROCK pathway in the spinal cord was, therefore, the primary target of our Fasudil therapeutic strategy [12]. Interestingly, we have observed that fasudil does not prevent the motor neuron loss that occurs in the $\mathrm{Smn}^{2 \mathrm{~B} / \text { - }}$ mice. In fact, the most apparent effects of fasudil appear to be the restoration of normal skeletal muscle growth and development, as well as increased post-synaptic EP area. A number of recent reports suggest that the SMN protein may have a muscle-intrinsic role that influences SMA pathology ([28-30] and JGB, unpublished data). Active RhoA has previously been shown to positively regulate the expression of myogenin $[38,39]$. Furthermore, work performed in avian and murine myoblasts shows that inhibition of ROCK promotes exit from the cell cycle and subsequent terminal differentiation [40]. Indeed, myoblasts treated with the ROCK inhibitor Y27632 display increased differentiation, cell fusion and myotube formation [40]. Fasudil's inhibition of the RhoA/ ROCK pathway most likely restores the normal skeletal muscle developmental program of $S m n^{2 B /-}$ mice via modulation of myoblast differentiation and fusion, as well as myogenin expression. The fasudil-dependent increase in myofiber size could lead to the subsequent increase in EP size. Indeed, a positive correlation has previously been established between myofiber size and motor EP size [41]. Furthermore, various reports suggest that post-synaptic differentiation and formation is initially muscle-dependent and motor axon-independent $[42,43]$. Our study, therefore, highlights two important points. Firstly, therapeutic strategies that improve skeletal muscle and EP growth should be considered when developing therapies for SMA. Secondly, ROCK inhibition may have positive outcomes in other pre-clinical disease models characterized by muscle atrophy and NMJ pathology.

Intriguingly, the dramatic increase in skeletal muscle myofiber size of fasudil-treated $S m n^{2 B /-}$ mice is not accompanied by changes in weight or strength, when compared to vehicle-treated $S m n^{2 B /-}$ mice. Previous studies have reported this phenomenon, providing a variety 


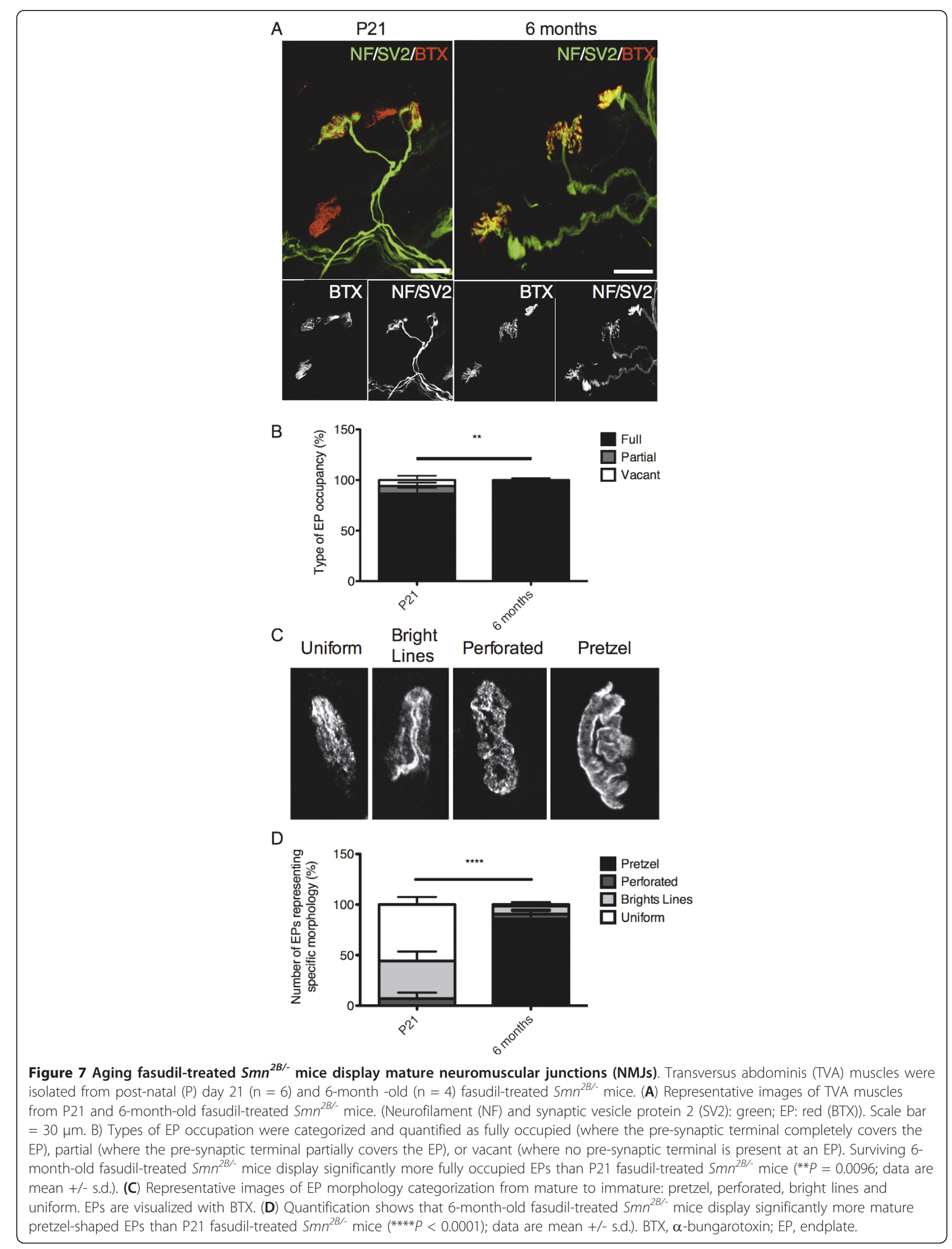


of potential explanations. In cases of sarcoplasmic hypertrophy, the non-contractile myofiber components expand while muscular strength remains unchanged [44]. Further, the characterization of a post-natal myogenin knockout mouse model revealed normal skeletal muscle size albeit with a $30 \%$ weight loss compared to control littermates [45]. The authors suggest that this phenotype is caused by a slower growth rate and perturbed energy homeostasis [45]. Finally, Rehfeldt et al. showed that mice homozygous for the Compact myostatin mutation $(C / C)$ display muscular hyperplasia and increased muscle weight but with a reduction in overall body weight [46]. The authors also identify a reduction in the number of capillaries per muscle in the $C / C$ mice, subsequently impacting oxidative metabolism [46]. Interestingly, recent work in the severe SMA mouse model demonstrated a significant decrease in the capillary bed density within skeletal muscle [47]. Thus, the findings mentioned above highlight the fact that an increase in muscle size and or weight does not necessarily positively correlate with an increase in body weight. Regardless, the restoration of myofiber growth and skeletal muscle development by fasudil, in the absence of weight gain, appears to be sufficient to provide therapeutic benefits to the $S m n^{2 B /-}$ mice.

In recent years, it has been postulated that SMA may be a die-back neuropathy, where the motor axons initially reach the EP but subsequently retract as disease progresses [48-50]. This hypothesis suggests that synapses are selectively vulnerable in SMA, with synapse loss preceding cell body degeneration. In addition, it has been suggested that neurons undergo compartmental degeneration, where the soma, axons and synapses of neurons possess specific and compartmentalized mechanisms of degeneration [51-53]. It therefore follows that therapeutics which target distal compartments of the cell, such as the synapse or axon, can be protective to the cell body. In our study, we show that while fasudil administration has little impact upon the initial loss of motor neurons, it dramatically increases myofiber and EP size in SMA mice. We therefore suggest that this improvement in post-synaptic parameters stabilizes the synaptic connections and subsequently protects the remaining motor neurons. Consistent with this observation, the surviving synapses constitute NMJs that will eventually develop and mature normally. Given the tight correlation between EP maturation and neuromuscular activity (reviewed in [54]), fasudil may indirectly improve NMJ transmission, subsequently ameliorating motor EP maturation. Alternatively, considering the crucial role of the actin cytoskeleton in the redistribution of acetylcholine receptors (AChRs) during post-synaptic remodeling $[55,56]$, fasudil's modulation of actin dynamics could directly restore normal AChR clustering. Clearly, the understanding and identification of fasudil's influence on
NMJ maturation in SMA mice requires further investigation. Nevertheless, our work highlights the applicability of the compartmental degeneration hypothesis to SMA pathogenesis and the potential of therapies aimed at preventing synaptic degeneration.

ROCK has evolved as an important therapeutic target in various models of cardiovascular disease, spinal cord injury and glaucoma (reviewed in [57-59]). Furthermore, the ROCK inhibitor fasudil, which has been approved in US clinical trials, has shown beneficial effects in patients with vasospastic angina [60], stable effort angina [61], general heart failure [62] and pulmonary hypertension [63]. It has now become evident that the pathogenic misregulation of the RhoA/ROCK pathway in various Smn-depleted cellular and animal models can also be modulated by the ROCK inhibitors Y-27632 and fasudil, leading to significant positive outcomes $[10,12,17]$.

\section{Conclusions}

The administration of fasudil to SMA mice significantly increases their lifespan without an obvious increase in Smn expression or preservation of spinal cord motor neurons. In fact, fasudil improves post-synaptic and skeletal muscle development. Our work underscores the importance of muscle as a therapeutic target in SMA and highlights the beneficial potential of ROCK inhibitors as a therapeutic strategy for SMA and for other degenerative diseases characterized by muscular atrophy and postsynaptic immaturity.

\section{Additional material}

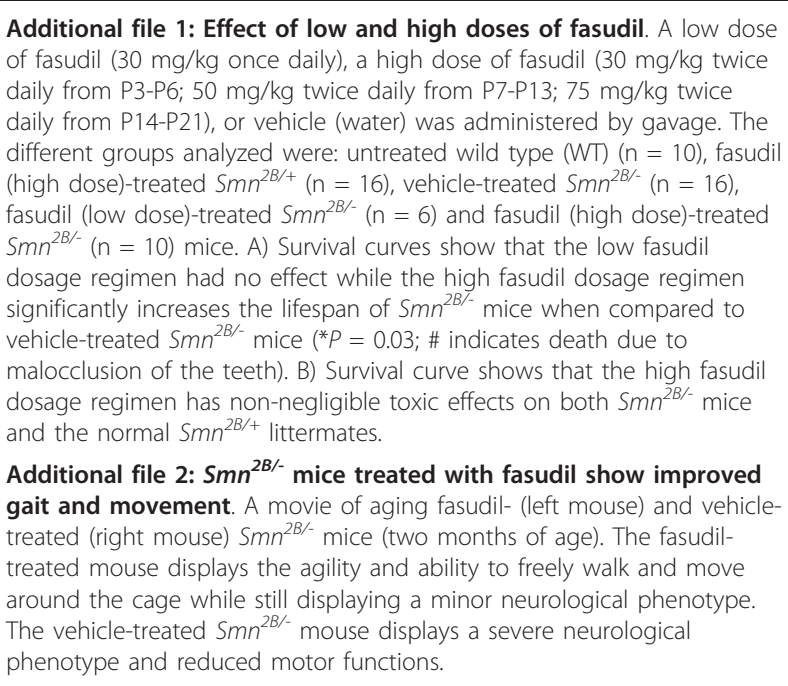

Abbreviations

a-BTX: a-bungarotoxin; AchR: acetylcholine receptor; CNS: central nervous system; EP: endplate; FDA: Food and Drug Administration; HDAC: histone deacetylase; NF: neurofilament; NMJ: neuromuscular junction; ROCK: Rho- 
kinase; SMA: spinal muscular atrophy; SMN: survival motor neuron; SV2: synaptic vesicle 2; TA: tibialis anterior; TVA: transversus abdominis.

\section{Acknowledgements}

We are grateful to the Kothary laboratory for helpful discussions. This project was funded by a grant from the Canadian Institutes of Health Research (ClHR), and The Muscular Dystrophy Association (USA) to RK. MB and JGB are recipients of a Frederick Banting and Charles Best CIHR Doctoral Research Award, LMM is a recipient of a Multiple Sclerosis Society of Canada Postdoctoral Fellowship, and RK is a recipient of a University Health Research Chair from the University of Ottawa.

\section{Author details}

'Ottawa Hospital Research Institute, 501 Smyth Road, Ottawa, ON, Canada K1H 8L6. 'Department of Cellular and Molecular Medicine, University of Ottawa, 451 Smyth Road, Ottawa, ON, Canada K1H 8M5. ${ }^{3}$ Department of Medicine, University of Ottawa, 451 Smyth Road, Ottawa, ON, Canada K1H $8 \mathrm{M} 5$.

\section{Authors' contributions}

$M B, L M M$ and RK conceived and designed the experiments. MB, LMM and $C L A$ performed the experiments. MB and LMM analyzed the data. JGB performed the initial characterization of misregulated myogenin expression in SMA skeletal muscle. MB and LMM wrote the paper. All authors read and approved the final manuscript.

\section{Competing interests}

The authors declare that they have no competing interests.

Received: 8 December 2011 Accepted: 7 March 2012

Published: 7 March 2012

\section{References}

1. Crawford TO, Pardo CA: The neurobiology of childhood spinal muscular atrophy. Neurobiol Dis 1996, 3:97-110.

2. Pearn J: Incidence, prevalence, and gene frequency studies of chronic childhood spinal muscular atrophy. J Med Genet 1978, 15:409-413.

3. Lefebvre $S$, Burglen $L$, Reboullet $S$, Clermont $O$, Burlet $P$, Viollet $L$, Benichou B, Cruaud C, Millasseau P, Zeviani M, et al: Identification and characterization of a spinal muscular atrophy-determining gene. Cell 1995, 80:155-165.

4. Jablonka S, Schrank B, Kralewski M, Rossoll W, Sendtner M: Reduced survival motor neuron ( $\mathrm{Smn}$ ) gene dose in mice leads to motor neuron degeneration: an animal model for spinal muscular atrophy type III. Hum Mol Genet 2000, 9:341-346.

5. Lorson $\mathrm{CL}$, Hahnen E, Androphy EJ, Wirth B: A single nucleotide in the SMN gene regulates splicing and is responsible for spinal muscular atrophy. Proc Natl Acad Sci USA 1999, 96:6307-6311.

6. Monani UR, Lorson CL, Parsons DW, Prior TW, Androphy EJ, Burghes AH, McPherson JD: A single nucleotide difference that alters splicing patterns distinguishes the SMA gene SMN1 from the copy gene SMN2. Hum Mol Genet 1999, 8:1177-1183.

7. Lefebvre S, Burlet P, Liu Q, Bertrandy S, Clermont O, Munnich A, Dreyfuss G, Melki J: Correlation between severity and SMN protein level in spinal muscular atrophy. Nat Genet 1997, 16:265-269.

8. Coovert DD, Le TT, McAndrew PE, Strasswimmer J, Crawford TO, Mendell JR, Coulson SE, Androphy EJ, Prior TW, Burghes AH: The survival motor neuron protein in spinal muscular atrophy. Hum Mol Genet 1997, 6:1205-1214

9. Boyer J, Bowerman M, Kothary R: The many faces of SMN: deciphering the function critical to spinal muscular atrophy pathogenesis. Future Neurol 2010, 5:873-890.

10. Bowerman M, Shafey D, Kothary R: Smn depletion alters profilin II expression and leads to upregulation of the RhoA/ROCK pathway and defects in neuronal integrity. J Mol Neurosci 2007, 32:120-131.

11. Bowerman $M$, Anderson CL, Beauvais A, Boyl PP, Witke W, Kothary R: SMN, profilin Ila and plastin 3: a link between the deregulation of actin dynamics and SMA pathogenesis. Mol Cell Neurosci 2009, 42:66-74.

12. Bowerman $M$, Beauvais $A$, Anderson $C L$, Kothary R: Rho-kinase inactivation prolongs survival of an intermediate SMA mouse model. Hum Mol Genet 2010, 19:1468-1478.
13. Luo $L$, Jan $L Y$, Jan $Y N$ : Rho family GTP-binding proteins in growth cone signalling. Curr Opin Neurobiol 1997, 7:81-86.

14. Govek EE, Newey SE, Van Aelst L: The role of the Rho GTPases in neuronal development. Genes Dev 2005, 19:1-49.

15. Luo L, O'Leary DD: Axon retraction and degeneration in development and disease. Annu Rev Neurosci 2005, 28:127-156.

16. Amano M, Ito M, Kimura K, Fukata Y, Chihara K, Nakano T, Matsuura Y, Kaibuchi K: Phosphorylation and activation of myosin by Rho-associated kinase (Rho-kinase). J Biol Chem 1996, 271:20246-20249.

17. Nolle A, Zeug A, van Bergeijk J, Tonges L, Gerhard R, Brinkmann H, Al Rayes S, Hensel N, Schill Y, Apkhazava D, Jablonka S, O'mer J, Srivastav RK, Baasner A, Lingor P, Wirth B, Ponimaskin E, Niedenthal R, Grothe C, Claus P: The spinal muscular atrophy disease protein SMN is linked to the rhokinase pathway via profilin. Hum Mol Genet 2011, 20:4865-4878.

18. DiDonato CJ, Lorson CL, De Repentigny $Y$, Simard L, Chartrand C, Androphy EJ, Kothary R: Regulation of murine survival motor neuron (Smn) protein levels by modifying Smn exon 7 splicing. Hum Mol Genet 2001, 10:2727-2736.

19. Hammond SM, Gogliotti RG, Rao V, Beauvais A, Kothary R, DiDonato CJ: Mouse survival motor neuron alleles that mimic SMN2 splicing and are inducible rescue embryonic lethality early in development but not late. PLoS One 2010, 5:e15887.

20. Schrank B, Gotz R, Gunnersen JM, Ure JM, Toyka KV, Smith AG, Sendtner M: Inactivation of the survival motor neuron gene, a candidate gene for human spinal muscular atrophy, leads to massive cell death in early mouse embryos. Proc Natl Acad Sci USA 1997, 94:9920-9925.

21. Butchbach ME, Edwards JD, Schussler KR, Burghes AH: A novel method for oral delivery of drug compounds to the neonatal SMNDelta7 mouse model of spinal muscular atrophy. J Neurosci Methods 2007, 161:285-290.

22. Murray LM, Comley LH, Thomson D, Parkinson N, Talbot K, Gillingwater TH: Selective vulnerability of motor neurons and dissociation of pre- and post-synaptic pathology at the neuromuscular junction in mouse models of spinal muscular atrophy. Hum Mol Genet 2008, 17:949-962.

23. Bowerman M, Murray LM, Beauvais A, Pinheiro B, Kothary R: A critical Smn threshold in mice dictates onset of an intermediate spinal muscular atrophy phenotype associated with a distinct neuromuscular junction pathology. Neuromuscul Disord 2012, 22:263-276.

24. Willmann R, Dubach J, Chen K: Developing standard procedures for preclinical efficacy studies in mouse models of spinal muscular atrophy: report of the expert workshop "Pre-clinical testing for SMA", Zurich, March 29-30th 2010. Neuromuscul Disord 2011, 21:74-77.

25. Yamaguchi $H$, Kasa M, Amano M, Kaibuchi K, Hakoshima T: Molecular mechanism for the regulation of rho-kinase by dimerization and its inhibition by fasudil. Structure 2006, 14:589-600.

26. Maekawa M, Ishizaki T, Boku S, Watanabe N, Fujita A, Iwamatsu A, Obinata T, Ohashi K, Mizuno K, Narumiya S: Signaling from Rho to the actin cytoskeleton through protein kinases ROCK and LIM-kinase. Science 1999, 285:895-898

27. Sumi T, Matsumoto K, Takai Y, Nakamura T: Cofilin phosphorylation and actin cytoskeletal dynamics regulated by rho- and Cdc42-activated LIMkinase 2. J Cell Biol 1999, 147:1519-1532.

28. Martinez-Hernandez R, Soler-Botija C, Also E, Alias L, Caselles L, Gich I, Bernal S, Tizzano EF: The developmental pattern of myotubes in spinal muscular atrophy indicates prenatal delay of muscle maturation. $J$ Neuropathol Exp Neurol 2009, 68:474-481.

29. Walker MP, Rajendra TK, Saieva L, Fuentes JL, Pellizzoni L, Matera AG: SMN complex localizes to the sarcomeric Z-disc and is a proteolytic target of calpain. Hum Mol Genet 2008, 17:3399-3410.

30. Mutsaers CA, Wishart TM, Lamont DJ, Riessland M, Schreml J, Comley LH, Murray LM, Parson SH, Lochmuller H, Wirth B, Talbot K, Gillingwater TH: Reversible molecular pathology of skeletal muscle in spinal muscular atrophy. Hum Mol Genet 2011, 20:4334-4344.

31. Ono $\mathrm{S}$, Minami $\mathrm{N}$, Abe $\mathrm{H}$, Obinata $\mathrm{T}$ : Characterization of a novel cofilin isoform that is predominantly expressed in mammalian skeletal muscle. J Biol Chem 1994, 269:15280-15286.

32. Arber S, Barbayannis FA, Hanser H, Schneider C, Stanyon CA, Bernard O, Caroni P: Regulation of actin dynamics through phosphorylation of cofilin by LIM-kinase. Nature 1998, 393:805-809.

33. Hasty P, Bradley A, Morris JH, Edmondson DG, Venuti JM, Olson EN, Klein WH: Muscle deficiency and neonatal death in mice with a targeted mutation in the myogenin gene. Nature 1993, 364:501-506. 
34. Passini MA, Cheng SH: Prospects for the gene therapy of spinal muscular atrophy. Trends Mol Med 2011, 17:259-265.

35. Shababi M, Mattis VB, Lorson CL: Therapeutics that directly increase SMN expression to treat spinal muscular atrophy. Drug News Perspect 2010, 23:475-482.

36. Chuang DM, Leng Y, Marinova Z, Kim HJ, Chiu CT: Multiple roles of HDAC inhibition in neurodegenerative conditions. Trends Neurosci 2009, 32:591-601.

37. Le TT, McGovern VL, Alwine IE, Wang X, Massoni-Laporte A, Rich MM, Burghes $\mathrm{AH}$ : Temporal requirement for high SMN expression in SMA mice. Hum Mol Genet 2011, 20:3578-3591.

38. Takano H, Komuro I, Oka T, Shiojima I, Hiroi Y, Mizuno T, Yazaki Y: The Rho family $\mathrm{G}$ proteins play a critical role in muscle differentiation. Mol Cell Biol 1998, 18:1580-1589.

39. Dhawan J, Helfman DM: Modulation of acto-myosin contractility in skeletal muscle myoblasts uncouples growth arrest from differentiation. J Cell Sci 2004, 117:3735-3748.

40. Castellani L, Salvati E, Alema S, Falcone G: Fine regulation of RhoA and Rock is required for skeletal muscle differentiation. J Biol Chem 2006, 281:15249-15257.

41. Waerhaug $\mathrm{O}$, Korneliussen $\mathrm{H}$ : Morphological types of motor nerve terminals in rat hindlimb muscles, possibly innervating different muscle fiber types. Z Anat Entwicklungsgesch 1974, 144:237-247.

42. Lin W, Burgess RW, Dominguez B, Pfaff SL, Sanes JR, Lee KF: Distinct roles of nerve and muscle in postsynaptic differentiation of the neuromuscular synapse. Nature 2001, 410:1057-1064.

43. Yang X, Arber S, William C, Li L, Tanabe Y, Jessell TM, Birchmeier C, Burden SJ: Patterning of muscle acetylcholine receptor gene expression in the absence of motor innervation. Neuron 2001, 30:399-410.

44. Kraemer WJ, Zatsiorsky VM: Science and practice of strength training. 2 edition. Champaign, IL: Human Kinetics; 2006.

45. Knapp JR, Davie JK, Myer A, Meadows E, Olson EN, Klein WH: Loss of myogenin in postnatal life leads to normal skeletal muscle but reduced body size. Development 2006, 133:601-610.

46. Rehfeldt C, Ott G, Gerrard DE, Varga L, Schlote W, Williams JL, Renne U, Bunger L: Effects of the compact mutant myostatin allele Mstn (Cmpt$\mathrm{dl} 1 \mathrm{Abc}$ ) introgressed into a high growth mouse line on skeletal muscle cellularity. J Muscle Res Cell Motil 2005, 26:103-112.

47. Somers E, Stencel Z, Wishart TM, Gillingwater TH, Parson SH: Density, calibre and ramification of muscle capillaries are altered in a mouse model of severe spinal muscular atrophy. Neuromuscul Disord

48. Kariya S, Park GH, Maeno-Hikichi Y, Leykekhman O, Lutz C, Arkovitz MS, Landmesser LT, Monani UR: Reduced SMN protein impairs maturation of the neuromuscular junctions in mouse models of spinal muscular atrophy. Hum Mol Genet 2008, 17:2552-2569.

49. Murray LM, Lee S, Baumer D, Parson SH, Talbot K, Gillingwater TH: Presymptomatic development of lower motor neuron connectivity in a mouse model of severe spinal muscular atrophy. Hum Mol Genet 2009, 19:420-433.

50. Ling KK, Gibbs RM, Feng Z, Ko CP: Severe neuromuscular denervation of clinically relevant muscles in a mouse model of spinal muscular atrophy. Hum Mol Genet 2012, 21:185-195.

51. Gillingwater TH, Ribchester RR: Compartmental neurodegeneration and synaptic plasticity in the WId(s) mutant mouse. J Physiol 2001, 534:627-639.

52. Gillingwater TH, Ribchester RR: The relationship of neuromuscular synapse elimination to synaptic degeneration and pathology: insights from WIdS and other mutant mice. J Neurocytol 2003, 32:863-881.

53. Coleman M: Axon degeneration mechanisms: commonality amid diversity. Nat Rev Neurosci 2005, 6:889-898.

54. Sanes JR, Lichtman JW: Development of the vertebrate neuromuscular junction. Annu Rev Neurosci 1999, 22:389-442.

55. Cartaud A, Stetzkowski-Marden F, Maoui A, Cartaud J: Agrin triggers the clustering of raft-associated acetylcholine receptors through actin cytoskeleton reorganization. Biol Cell 2011, 103:287-301.

56. Dobbins GC, Zhang B, Xiong WC, Mei L: The role of the cytoskeleton in neuromuscular junction formation. J Mol Neurosci 2006, 30:115-118.

57. Satoh K, Fukumoto Y, Shimokawa H: Rho-kinase: important new therapeutic target in cardiovascular diseases. Am J Physiol Heart Circ Physiol 2011, 301:H287-296.
58. Cadotte DW, Fehlings MG: Spinal cord injury: a systematic review of current treatment options. Clin Orthop Relat Res 2011, 469:732-741.

59. Wierzbowska J, Robaszkiewicz J, Figurska M, Stankiewicz A: Future possibilities in glaucoma therapy. Med Sci Monit 2010, 16:RA252-259.

60. Masumoto A, Mohri M, Shimokawa H, Urakami L, Usui M, Takeshita A: Suppression of coronary artery spasm by the Rho-kinase inhibitor fasudil in patients with vasospastic angina. Circulation 2002, 105:1545-1547.

61. Shimokawa H, Hiramori K, linuma H, Hosoda S, Kishida H, Osada H, Katagiri T, Yamauchi K, Yui Y, Minamino T, Nakashima M, Kato K: Antianginal effect of fasudil, a Rho-kinase inhibitor, in patients with stable effort angina: a multicenter study. J Cardiovasc Pharmacol 2002, 40:751-761.

62. Kishi T, Hirooka Y, Masumoto A, Ito K, Kimura Y, Inokuchi K, Tagawa T, Shimokawa H, Takeshita A, Sunagawa K: Rho-kinase inhibitor improves increased vascular resistance and impaired vasodilation of the forearm in patients with heart failure. Circulation 2005, 111:2741-2747.

63. Fukumoto Y, Matoba T, Ito A, Tanaka H, Kishi T, Hayashidani S, Abe K, Takeshita A, Shimokawa H: Acute vasodilator effects of a Rho-kinase inhibitor, fasudil, in patients with severe pulmonary hypertension. Heart 2005, 91:391-392.

\section{Pre-publication history}

The pre-publication history for this paper can be accessed here: http://www.biomedcentral.com/1741-7015/10/24/prepub

doi:10.1186/1741-7015-10-24

Cite this article as: Bowerman et al:: Fasudil improves survival and promotes skeletal muscle development in a mouse model of spinal muscular atrophy. BMC Medicine 2012 10:24.

\section{Submit your next manuscript to BioMed Central and take full advantage of:}

- Convenient online submission

- Thorough peer review

- No space constraints or color figure charges

- Immediate publication on acceptance

- Inclusion in PubMed, CAS, Scopus and Google Scholar

- Research which is freely available for redistribution

Submit your manuscript at www.biomedcentral.com/submit 